\title{
SENTIDOS DE CURRÍCULO NA ESCOLA MUNICIPAL GLAUBER DOS SANTOS BORGES: O QUE DIZEM OS PROFESSORES
}

\author{
Viviane Ribeiro Primo do Carmo \\ Clarissa Bastos Craveiro \\ Maicon Jefferson da Costa Azevedo ${ }^{3}$
}

\section{INTRODUÇÃO}

Este texto busca compartilhar uma pesquisa sobre sentidos e discursos de Currículo de docentes da Escola Municipal Glauber dos Santos Borges localizada na Costa Verde ${ }^{4}$ do Rio de Janeiro. O interesse por esse estudo surgiu em sala de aula, no curso de Licenciatura em Pedagogia da Universidade Federal Fluminense (UFF) a partir das discussões da disciplina de Currículo. Durante a disciplina ${ }^{5}$, começaram a emergir vários questionamentos a respeito da temática de Currículo, tais como: a significação de Currículo por parte dos profissionais da educação da escola em que estagiava $^{6}$, a relação entre produção curricular e prática docente, a produção contínua de currículo na escola e outros. Na esteira dos estudos da disciplina, vivência na escola e questionamentos sobre essas temáticas ocasionados a partir dos espaços de discussão na Universidade foi se gestando um campo fértil para pesquisa, no qual nos deparamos agora.

Nesse caminho também foi possível perceber a necessidade de se pensar as políticas curriculares para a formação de professores que endereçam sentidos para os docentes da rede municipal de Mangaratiba, bem como a produção curricular na escola, tendo em vista a pluralidade

\footnotetext{
${ }^{1}$ É Pedagoga e trabalha na Rede Municipal de Educação de Mangaratiba, no Estado do Rio de Janeiro, Brasil. Endereço de contato: vivianeribeiro@id.uff.br.

${ }^{2}$ É professora da Universidade Federal Fluminense no campus de Angra dos Reis, no Estado do Rio de Janeiro, Brasil. É líder do Grupo de Pesquisas Curriculares (GPeC). Endereço de contato: clarissacraveiro@id.uff.br.

${ }^{3}$ É professor do Centro Federal de Educação Tecnológica Celso Suckow da Fonseca (CEFET/RJ), no Estado do Rio de Janeiro, Brasil. É integrante do grupo de pesquisa Currículo, Docência e Culturas (CDC/UFF). Endereço de contato: maiconbio@gmail.com.

${ }^{4}$ Costa Verde é uma região do Estado do Rio de Janeiro que compreende os seguintes municípios: Angra dos Reis, Mangaratiba, Paraty, Itaguaí, Rio Claro (FONTE: http://www.ceperj.gov.br).

${ }^{5}$ A disciplina foi cursada em 2015, a continuação dessa pesquisa até 2017 com a conclusão da graduação.

${ }^{6}$ Ano de 2016 passei em concurso público para o município de Mangaratiba como auxiliar de secretaria, atuando no ano de 2017 como secretária nesta escola o que facilitou a continuidade da pesquisa após o término da licenciatura da Pedagogia em 2017.
} 
de concepções que os sujeitos da escola defendiam, buscando valorizar as suas singularidades e diferenças no universo da mesma rede municipal de Educação. Dentre a complexidade dessas relações, entender o espaço da diferença ${ }^{7}$ na unidade da rede municipal, também se tornou um grande desafio para a pesquisa. E, assim, compreendemos que ouvir as vozes dos professores poderia ser um caminho fértil para tecer algumas considerações e/ou fechamentos provisórios, precários e contingentes $^{8}$ que poderiam sinalizar ao menos, possibilidades de compreensões para este momento de produção de sentidos na escola.

No período inicial de pesquisa, não podemos deixar de destacar a contribuição da Iniciação Científica fomentada pela FAPERJ, para ampliar os olhares da pesquisa no campo do Currículo focando a discussão em torno de questões relacionadas à formação de professores. Utilizamos como referencial teórico alguns autores que destacamos, tais como: Alice Casimiro Lopes, Elizabeth Macedo, Stephen Ball, que também nortearam os estudos e análises posteriores no contexto da escola municipal. Durante a pesquisa, o Ciclo de Políticas de Ball (1992,1994) foi um importante instrumento heurístico ${ }^{9}$ para pensar como se organizam e produzem as políticas curriculares do Plano Municipal de Educação (PME), do Projeto Político Pedagógico (PPP) da Escola Municipal Glauber dos Santos Borges e as produções e reinterpretações dos professores no contexto da prática. Todavia, para esse texto, buscamos dar uma maior visibilidade para os entendimentos de currículo apropriados no ambiente acadêmico da Universidade e os sentidos de currículo defendidos nos discursos dos professores.

Também é mister esclarecer que dentre os objetivos que nortearam essa pesquisa destacamos: ampliar conhecimentos a partir da flutuação de sentidos sobre o entendimento do que é currículo por parte dos professores da Escola Municipal Glauber dos Santos Borges da rede municipal de ensino de Mangaratiba; compreender "o currículo praticado" como "currículo texto" e, vivenciar a negociação de sentidos no contexto da prática.

\footnotetext{
${ }^{7}$ Diferença aqui entendida conforme Lopes; Macedo (2011) "um currículo marcado pela diferença é um currículo concebido como cultura (...) um processo de produção de sentidos, sempre híbridos" (p.227).

8 Destaco aqui que a formação discursiva "é sempre um conjunto articulado, mas heterogêneo, de discursos, ou seja, de sistemas de regras de produção de sentido" (LACLAU apud BURITY, 2008, p. 42) que hegemonizam um dado discurso, em um dado momento, dentro de uma pluralidade de sentidos.

9 Segundo Mainardes (2006) "essa abordagem foi formulada por Stephen Ball e Richard Bowe e tem sido utilizada em diferentes contextos como referencial teórico-analítico para o estudo de políticas educacionais", e ela "oferece instrumentos para uma análise contextualizada de programas e políticas educacionais desde sua formulação até a sua implementação no contexto da prática" (p. 48).
} 
Entendemos que tudo parte de processos de hibridização ${ }^{10}$ ou de produção de textos ${ }^{11}$ e de discurso. Ou seja, não há currículo texto de um lado e currículo praticado de outro para observarmos as relações entre eles.

No que diz respeito à compreensão de currículo, concordamos com Lopes e Macedo (2011) ao defenderem que há certa impossibilidade de se precisar o que seja currículo pois,

[...] não é possível responder "o que é currículo" apontando para algo que lhe é intrinsecamente característico, mas apenas para acordos para os sentidos de tal termo, sempre parciais e localizados historicamente. Cada "nova definição" não é apenas uma nova forma de descrever o objeto currículo, mas parte de um argumento mais amplo no qual a definição se insere. A "nova definição" se posiciona, seja radicalmente contra, seja explicitando suas insuficiências, em relação às definições anteriores, mantendo-se ou não no mesmo horizonte teórico delas (LOPES e MACEDO, 2011, p. 19-20).

Trabalhamos com essa "nova definição" (LOPES e MACEDO, 2011), pois o termo carrega em si um conjunto de perspectivas em que as interpretações são descobertas na medida em que reinterpretamos o texto, a cada leitura. Esse posicionamento teórico nos ajudou a repensar as propostas curriculares do município na continuidade da pesquisa, pois na escola há um enorme distanciamento do discurso que vem sendo defendido pela Secretaria Municipal de Educação (SME) e os discursos dos docentes e demais funcionários no contexto da prática da escola.

Por hora, organizamos essa leitura a partir das seguintes seções: sentidos a respeito das concepções de currículo, a contextualização da escola pesquisada e alguns discursos de professores e funcionários e, por fim, apontamos algumas considerações provisórias a respeito do processo de produção curricular com base nas experiências vivenciadas na escola.

\footnotetext{
${ }^{10}$ De acordo com Ball (2001) "hibridização é a combinação de lógicas globais, distantes e locais" (p.102).

${ }^{11}$ Currículo texto e produção de textos de acordo com "a concepção da política de currículo vinculada à perspectiva pósestruturalista. Esse entendimento diz respeito ao currículo como "criação ou enunciação de sentidos" (LOPES; MACEDO, 2011, p. 28) e tenta desconstruir concepções de currículo associadas à seleção de conteúdos, à aquisição pragmática de habilidades ou ao controle social (apud CRAVEIRO, 2014, p.35).
} 


\section{SENTIDOS E CONCEPÇÕES DE CURRÍCULO EM DIÁLOGO}

As abordagens pautadas na centralidade do Estado $^{12}$, influentes em diversas políticas curriculares, começaram a ser questionadas pelas teorias baseadas na modificação das concepções da categoria poder, desenvolvidas principalmente por Michel Foucault e Jacques Derrida desde os anos 1960. Ainda que a preocupação desses autores não esteja relacionada a questões curriculares, eles representam marcos no que diz respeito a uma nova lógica para pensar a realidade através das práticas discursivas e assim tiveram impacto no campo do Currículo. Foucault (2003) através de seus estudos traz uma nova noção de poder a se pensar, o poder disciplinar, descentrado, relacionado à vigilância, à regulação dos grupos sociais e do indivíduo e seu corpo. Quanto mais coletivas e organizadas sejam as instituições, mais se exercerá o poder disciplinador. A contribuição de Derrida é através da influência da linguística, a partir do descentramento do significado das palavras. Conforme Hall (2006, p. 41), para Derrida

o significado é inerentemente instável: ele procura o fechamento (a identidade), mas ele é constantemente perturbado (pela diferença). Ele está constantemente escapulindo de nós. Existem sempre significados suplementares sobre os quais não temos qualquer controle, que surgirão e subverterão nossas tentativas para criar mundos fixos e estáveis.

As perspectivas pós-estruturalistas no campo da política curricular que desconfiavam dos discursos e das afirmações sobre conhecimento da década de 1970, por compreenderem que o poder é descentrado e as influências de mudança no social não são provenientes apenas das relações econômicas mas dos discursos que envolvem o social, ganharam mais ênfase no Brasil na década de 2000.

As análises pós-estruturalistas para o currículo e para pensar a política, segundo Cherryholmes (1993), permitem-nos vislumbrar os argumentos acadêmicos e teóricos não mais pautados em uma certeza de verdade, mas como passíveis de contestação, de desconfiança da autoridade legitimada e de encarar as relações de poder, as estruturas sociais, bem como os discursos de política curricular como criados por discursos que explicam acontecimentos históricos e práticas políticas. Dessa maneira, alguns interesses são atendidos e outros excluídos, através da sustentação discursiva de determinados valores ou ideologias.

\footnotetext{
12 Por exemplo: Apple (1989), Althusser (1982, 1998), Baudelot e Establet (1971), Bowles e Gintis (1976), Bourdieu e Passeron (1975) e Young (1971).
}

Revista Teias v. $19 \bullet$ n. 52 • 2018 (Jan./Mar.): Estudos da infầncia - diálogos contemporâneos 
Isso é possível, pois, segundo Hall (2006), os discursos são produzidos e com isso produzem sentidos com os quais são organizados processos de identificação e assim constroem identidades fluidas. Esses processos de identificação vão sofrendo deslocamentos e são substituídos por discursos constituídos por outras demandas. Podemos dizer que o(s) discurso(s) centrais são substituídos por uma "pluralidade de centros de poder" (HALL, 2006, p. 16), na medida em que esse processo sofre constantemente descontinuidade, fragmentação, ruptura e deslocamento e o discurso estável do passado abre possibilidades de novas articulações. Essas perspectivas aparecem como a desconstrução das grandes narrativas das teorias críticas que lutaram contra os currículos eficientistas e que eram consideradas como a possibilidade de mudança, de fuga à lógica do capitalismo.

De acordo com Lopes e Macedo (2011), as teorias críticas defendiam que a reprodução econômica era reproduzida no interior da escola como forma de controle social e cultural. As relações sociais eram percebidas na relação de antagonismo entre capital e trabalho. Entretanto, na perspectiva pós-estruturalista esse discurso é descentrado da estrutura econômica e é construído pela linguagem. Conforme argumentam Mendonça e Rodrigues (2008), o social é formado por uma infinidade de identidades que são constituídas a partir de relações discursivas antagônicas que não se restringem ao antagonismo de classe; há vários lócus particulares de antagonismos sociais possíveis nas relações sociais contemporâneas.

Todavia as teorias críticas não superam as teorias eficientistas ou as teorias progressivistas; apresentam aspectos de discordância teóricos, metodológicos e políticos. Não há um sentido de evolução histórica, social ou cultural que, ao longo do tempo, vá se modificando. Essas abordagens, na política curricular, são apenas formas de endereçar sentidos para o social. As lutas envolvem poder e, por isso, constantes processos de hegemonização pelas demandas que são defendidas.

As perspectivas pós-estruturalistas operam em uma lógica diferente das teorias críticas e eficientistas. A luta não está localizada nas barreiras da estrutura ou da agência e nem há um lugar idealizado a chegar através da emancipação dos sujeitos. As relações de poder estão em outra ordem, na ordem do discurso, na ordem do processo de significação, e fazem parte da constituição do sujeito e lutam por alcançar as demandas que percebem como necessárias. As relações sociais são significadas a partir da prática discursiva, por isso, sendo o social 'significado', deixa de ser uma instância a ser desvendada, revelada, e passa a algo passível de ser compreendido por meio das significações contingentes e precárias em que o discurso é fixado temporariamente.

Segundo Lopes e Macedo (2011), o pós-estruturalismo dialoga com autores estruturalistas, questionando alguns de seus pressupostos, bem como dialoga com o pensamento pós-moderno que 
questiona a Modernidade. Aproxima-se dos estruturalistas no que diz respeito a compreender que a linguagem constrói o mundo ao invés de representá-lo. Mas afasta-se deles ao problematizar que o mundo não pode ser entendido por meio das estruturas que o constituem através da linguagem e, por isso, reconfigura o entendimento da concepção de linguagem, pois

a linguagem não representa a realidade, qualquer significado pode ser atribuído a um significante e isso é um processo cultural. $\mathrm{O}$ que nos permite atribuir um significado a um significante é a sua diferença em relação a outros significantes (LOPES; MACEDO, 2011, p. 39).

Entendo poder, conforme Lopes e Macedo (2011, p. 40), “como função do discurso. A capacidade de unificar um discurso é em si um ato de poder”. Com esse entendimento, pensamos que a questão não é tentar eliminar o poder, rompendo com determinadas estruturas sociais, mas compreender os processos de identificação produzidos pelo discurso.

Por isso, o poder continuará a se manifestar em diferentes processos de significação, não apenas nos processos de significação originados por explicações de ordem econômica, e algumas vezes representado pela instância do poder do Estado como produtor da política. A política curricular analisada pelo viés pós-estruturalista busca compreender os processos de constituição de discursos hegemônicos ou de como se tornaram hegemônicos. É sempre uma busca por entender o jogo político que busca defender um determinado discurso. A definição da luta é que permite o discernimento da posição do sujeito nesse processo. Nenhum discurso pode ser aceito como definitivo, natural, tradicional ou reconhecido por qualquer argumento universal. É importante nessa luta perceber a construção discursiva, de onde vem esse discurso e para onde se encaminham seus interesses.

A possibilidade de análise discursiva traz a enunciação de sentidos como produzida por atos de poder. Os sentidos que são legitimados no currículo, nas políticas curriculares, o são por construções discursivas hegemônicas e contingentes. Segundo Mendonça e Rodrigues (2008), o discurso é o resultado do princípio articulador de sentidos. O entendimento de que a construção de sentidos é significada a partir de qualquer construção discursiva sinaliza um desafio na análise das políticas curriculares na medida em que entender as tentativas de fixação de sentidos nos textos curriculares é também buscar entender os sentidos que buscam hegemonizar-se.

O contato com a abordagem discursiva no período da pesquisa e a participação no Grupo de Pesquisas Curriculares (GPeC) da Universidade Federal Fluminense (UFF) foram fundamentais para 
desconstruir e construir, ainda que provisoriamente, os entendimentos a respeito das políticas curriculares do município e da produção curricular na escola nesse período.

\section{A ESCOLA E A PRODUÇÃO DE SENTIDOS DE CURRÍCULO}

A escola na qual gostaríamos de compartilhar nossa experiência que se inicia em 2016 é uma escola pequena no município de Mangaratiba, possui 7 turmas de Educação Infantil e 10 turmas de Ensino Fundamental de primeiro segmento. Em 2015, tivemos várias conversas com 2 professoras da Educação Infantil e 3 do Ensino Fundamental que aceitaram dialogar sobre temas relacionados a construção curricular e a proposta do Projeto Municipal de Educação (PME) que a Secretaria de Educação (SME) vinha implantando na rede municipal de Mangaratiba. Além dessas professoras, a equipe gestora da época quis participar nas discussões sobre currículo demonstrando grande interesse com o tema proposto.

A escola foi criada pelo decreto Municipal $n^{\circ} 735$. Atualmente atende crianças a partir dos 3 anos de idade em turmas da Educação Infantil até o $3^{\circ}$ ano do Ciclo de Alfabetização.

Inicialmente a escola atendia somente turmas de Educação Infantil. Até a construção do prédio atual, a escola funcionou em outros estabelecimentos por exemplo: no local onde atualmente encontra-se o posto de saúde do Distrito; no local onde atualmente funciona a quadra pública de esportes e no antigo prédio de uma escola Estadual, próximo à praia e que já foi demolido.

Com o passar dos anos e o aumento na demanda, a escola passou a atender também algumas séries dos anos iniciais do Ensino Fundamental, e, com isso, houve a necessidade da construção de um prédio para abrigar em caráter definitivo a nova sede da escola.

Esta nova sede foi inaugurada no dia 04 de setembro de 2003 com o nome: Escola Municipal Glauber dos Santos Borges. Destacamos que esse distrito é o $2^{\circ}$ maior distrito do Município. Fazem parte da Secretaria Municipal de Educação de Mangaratiba: 3 escolas municipais, uma creche de Educação Infantil que atende até o nível 3 (crianças de 4 anos), a escola da pesquisa que atende a Educação Infantil e Ensino Fundamental do $1^{\circ}$. segmento e uma outra escola que atende o 20. segmento do Ensino Fundamental em parceria com o Estado que atende o Ensino Médio e cede espaço para o município. Além das escolas do município, há uma escola particular. Todas as crianças do distrito e entorno, se distribuem dentre essas escolas. Dessa maneira, sinalizamos a importância da escola para a região, para a formação dos alunos e para a SME.

Desde a data de sua inauguração, em 2003, houve um crescimento bastante expressivo no número de alunos que são atendidos anualmente, inclusive houve a necessidade de ampliações 
estruturais. Foi criado um anexo, que constitui novos espaços onde funcionam mais três salas de aula e que foi inaugurado em 16 de março de 2007 e recebeu o nome de Anexo Professora Valterina.

Um dado que nos chamou a atenção no início da pesquisa foi o número dos cargos comissionados/contratados no município, 95\% dos funcionários da Educação tinham cargos comissionados/contratados. Na Escola Municipal Glauber dos Santos Borges, haviam 16 funcionários efetivos e 25 funcionários com cargos comissionados/contratados.

No ano de 2015 foi deferido o edital para concurso público na área da Educação, um evento que não ocorria no município há aproximadamente 11 anos. Com esse concurso, em 2016, a substituição dos funcionários contratados por efetivos trouxe uma mudança grande para o cotidiano escolar, todavia, o contexto ao qual nos referimos neste texto é anterior a essa mudança e, majoritariamente composto por funcionários contratados.

\section{SENTIDOS DE CURRÍCULO}

Buscando compreender a proposta das práticas dos professores e os entendimentos em relação à construção curricular na escola, iniciamos algumas conversas informais, sobre os significados de currículo. Ao buscar as conversas informais operamos com a ideia de que estas, na verdade, fazem emergir sentidos e concepções importantes que muitas vezes não estão em evidência. Além disso, estas também poderem ser compreendidas como uma construção personalizada, mediada pela relação entre a história pessoal e a história social a qual os indivíduos estão submetidos. Desta forma, com o intuito de capturar informações subjetivas que nos ajudem a compreender a experiência vivida pelos entrevistados, conversamos com 35 funcionários de 45 e, pudemos perceber uma flutuação de sentidos no significado de Currículo.

Estas conversas ocorreram no período de transição entre a troca dos funcionários comissionados/contratados pelos efetivos oriundos do concurso público. Atualmente o quadro de funcionários sofreu uma mudança extrema, passando a ter $95 \%$ de funcionários efetivos.

Neste estudo ao trabalharmos com as conversas informais, na verdade a compreendemos como uma narrativa: uma sequência singular de eventos reais ou imaginários que envolvem seres humanos e os tem como personagens ou autores (BRUNER, 2002). Tomados deste sentido, buscamos operar com a perspectiva da pesquisa narrativa, entendida por Paiva (2008) como a "metodologia que consiste na coleta de histórias sobre determinado tema, onde o investigador encontrará informações para entender determinado fenômeno" (p. 263). Este tipo de trabalho oferece ao entrevistador a 
possibilidade participar da coleta de dados, de motivar o entrevistado/narrador a contar fatos de forma particular. Neste sentido cada indivíduo é entendido como um universo singular arquitetado sobre a interpretação pessoal da estrutura social e do contexto histórico vivido (GOLDENBERG, 2004).

Muylaert et al. (2014) ressalta que é na interação, na troca, no diálogo entre entrevistado e narrador que emergem histórias, discursos e explicações que revelam a sua forma de compreender um determinado fenômeno. De acordo com Alves (2008, p.131) "nós somos o que contamos".

Ao ouvi-los verificamos que a concepção adotada pelo primeiro grupo de funcionários que chamaremos de A, funcionários estes em sua totalidade com formação em Nível Médio na modalidade Formação de Professores, é uma concepção pautada no senso comum, onde a face mais evidente, mais prática do currículo pode ser acessada. Encontramos discursos que apresentam o currículo como uma grade de conteúdo, matérias a serem seguidos por cada disciplina para se alcançar determinado objeto no final do ano letivo. Neste grupo tivemos $80 \%$ dos entrevistados definindo currículo como um documento histórico, que relata a trajetória educacional e as experiências profissionais de uma pessoa, chegando a mencionar o currículo profissional, ou seja, "currículo vitae".

Nessas conversas, iniciadas sobre o entendimento de currículo, a preocupação por significar currículo ou o entendimento dos âmbitos de ação de currículo foram grandes por parte desse grupo, pelo desconhecimento que manifestavam pelo que poderia ser significado como "currículo", como por exemplo:

Você fala currículo... Grade curricular da escola ou currículo escolar, a grade que vem, que você fala? (Narrador 113)

É um conjunto de infor... Não é informações... Como que eu posso dizer? Um conjunto de (...) de regras, não é? Vamos dizer regras, a serem seguidas, a serem... Metas, regras, a serem seguidas e cumpridas (Narrador 2).

Ah, é difícil responder isso. Depende! Porque, assim, eu entendo várias coisas de currículo. Depende de certas, de várias situações. Por exemplo, se for o do professor, né? Se for o do inspetor... Depende da função que você vai exercer, se for currículo de funcionários (Narrador $3)$.

Eu entendo que é uma junção de coisas que você recolhe pra saber de uma determinada pessoa, de uma determinada empresa, é,

\footnotetext{
${ }^{13}$ Os nomes não aparecem nesse texto para preservar a identidade dos profissionais entrevistados.
} 
conjunto de informações que você recebe, pra saber de uma determinada pessoa, de uma determinada empresa, alguma coisa assim (Narrador 4).

Todavia, apesar das diferenças nos entendimentos, destacamos como comum à essas narrativas o potencial do currículo como uma certa normatização, seja pela grade escolar, regras ou informações profissionais. Talvez uma consequência das inúmeras reformas educacionais ocorridas no Brasil nos últimos anos, sobretudo a partir da década de $1990^{14}$, em que a normatização de práticas pedagógicas deixa em evidência a face mais prática das reformas curriculares.

Ao ouvirmos o segundo grupo, que chamaremos de B, em sua maioria professores com formação superior em Pedagogia, e até especialização, percebemos um discurso relacionando o termo currículo a algo mais subjetivo, ou seja, uma flutuação de sentidos entre a prática e a teoria.

Dentro do grupo B também tivemos uma flutuação constante de significação do termo currículo, e pudemos perceber que a instituição superior de ensino frequentada pelos professores serviu como influência de suas convicções. Chamaremos de B1 os que concluíram seu curso em faculdades privadas, à distância ou não, e de B2 os que concluíram seus cursos em universidades públicas. Os que concluíram em universidades públicas, mas fizeram seu curso à distância, podem se encaixar no grupo B1.

O grupo B1 teve um discurso vago sobre a significação de currículo, apresentaram grande dificuldade em conversar sobre o tema proposto, oscilando suas respostas, e em sua maioria criando divergências em sua definição.

Currículo é toda a vivência do aluno. Faz parte dos conteúdos programáticos, a experiência de vida do aluno e o que a escola contribui prá esse contexto (Narrador 5).

É, o enquadramento... A gente, a gente que trabalha na educação, a gente entende por quê, que o currículo a gente trabalha com as especialidades do aluno, a gente trabalha com a educação integrada, com toda a integração de disciplina, das áreas de conhecimento do aluno. A gente trabalha com um momento de pensar do aluno, né? A gente faz um... Por exemplo, se for educação infantil, a gente trabalha com o pensar, com a produção, com a educação como um todo, né? Por exemplo, a gente, na educação infantil... (Narrador 6).

\footnotetext{
${ }^{14}$ Desde a promulgação da Lei de Diretrizes e Bases de 1996 o ensino por competências tem se tornado a principal forma de organização das propostas curriculares brasileiras e também dos sistemas de avaliações nacionais, estaduais e municipais do país.
} 
É o meio pelo qual a escola se organiza, propõe suas orientações para a prática de quando e como ensinar e avaliar. $O$ currículo escolar deve ser construído a partir do PPP para viabilizar a pratica pedagógica da escola (Narrador 7).

Ainda que esses professores buscassem de alguma forma ampliar sentidos de Currículo para além da questão disciplinar trazendo aspectos da experiência do cotidiano, da produção intelectual do aluno, a flutuação desses sentidos no contexto das conversas mais que indicar possibilidade de ampliação do tema pelos seus muitos significados, apresentavam-se com dúvidas e insegurança quanto a conversa sobre essa temática e não relacionavam os sentidos de currículo que mencionavam entre si. A dúvida dos docentes entrevistados talvez possa ser traduzida como uma tentativa de adequação entre o pensar e o fazer pedagógico. Se por um lado temos elementos oriundos da formação que apontam para a valorização do saber cotidiano dos alunos e das experiências pedagógicas, o que em certa medida denota uma expansão do conceito de currículo. Por outro, temos os imperativos do cotidiano escolar que impõe normas e regras a serem cumpridas para que os objetivos propostos no planejamento sejam alcançados. Compõem este cenário elementos compreendidos como técnicos ou práticos do currículo: o planejamento, as grades curriculares, tempo que cada disciplina disporá semanalmente, as competências e objetivo a serem alcançados, por exemplo. Cabe destacar que estes aspectos ditos mais técnicos ou práticos do currículo foram valorizados no cotidiano escolar a partir de uma perspectiva eficientistas ${ }^{15}$ de currículo, que segundo Lopes e Macedo (2011) dominaram os currículos brasileiros até meados da década de 1980.

O grupo B2 foi mais seguro em suas respostas, e sua grande maioria definiu Currículo como algo que não pode ser atribuído mero significado, aproximando-se mais da concepção de Lopes e Macedo (2011),

não é possível responder "o que é currículo" apontando para algo que lhe é intrinsecamente característico, mas apenas para acordos para os sentidos de tal termo, sempre parciais e localizados historicamente. Cada "nova definição" não é apenas uma nova forma de descrever o objeto currículo, mas parte de um argumento mais amplo no qual a definição se insere. A "nova definição" se posiciona, seja radicalmente contra, seja explicitando suas insuficiências, em

\footnotetext{
${ }^{15} \mathrm{O}$ eficientismo foi defendido por John Franklin Bobbit (1876 - 1918) que na década de 1910 trabalhou com a ideia de um currículo com a função de preparar o aluno para a vida economicamente ativa. Orientado pelo Taylorismo, o currículo seria formulado por especialistas que identificariam os objetivos a serem alcançados e as tarefas ideais para formar o aluno/trabalhador. É o conceito de eficiência que norteia esta concepção, o conhecimento veiculado pela escola precisa ser útil e prático.
} 
relação às definições anteriores, mantendo-se ou não no mesmo horizonte teórico delas (LOPES e MACEDO, 2011, pág. 19-20).

Para eles, Currículo significava,

Currículo é tudo. Conteúdo a serem ensinados e aprendidos; as experiências de aprendizagem escolares a serem vividas pelos estudantes; os planos pedagógicos elaborados por professores, escolas e sistemas educacionais (Narrador 8);

Um currículo apoiado nas concepções de homem, sociedade e cultura dentro da perspectiva histórico-cultural. Um roteiro norteador que pode sofrer mudanças conforme as necessidades que surgirem (Narrador 9).

Esse grupo de professores manifestava tranquilidade e autoconfiança nas conversas sobre a temática e sobre as questões do cotidiano escolar, possivelmente consequência da relação dialógica entre teoria e prática compartilhadas na universidade.

Todavia, foi possível vivenciar no período de pesquisa na escola uma falta de articulação entre os professores e funcionários no que diz respeito às questões pedagógicas. Essa situação nos remeteu a um dado que nos pareceu interessante neste período; relacionar essa falta de articulação entre os professores na escola e a formação de nível médio dos gestores. Pensamos que a diferença de titulação e de formação entre os funcionários pudesse ser uma das causas para a pouca interação pedagógica na escola, e fizesse com que os gestores se sentissem um pouco inibidos ante a formação universitária dos demais professores.

Há ainda um terceiro grupo de funcionários que só possuem o Ensino Fundamental, completo ou não, chamaremos este grupo de F. Os discursos levantados neste último grupo, foi para nós alguns dos mais interessantes, pois $80 \%$ das narrativas souberam sustentar suas convicções, mesmo que de maneira simples. Foram concisos em suas respostas e demostraram um entendimento mais próximo do grupo B2, que do grupo A e B1.

Eu acho, assim, currículo escolar é muito importante porque dá uma visão do que você estudou, como você foi nos estudos, o que você pode fazer, que nível de, de... Algo que você possa fazer, você pode ser avaliado pelo seu currículo. É ali que você é avaliado (narrador 10).

Currículo, pra mim, é a nossa formação e a nossa experiência. Tudo que a gente aprendeu e tudo que a gente vivenciou com relação ao trabalho e a formação em si (Narrador 11). 
É possível perceber, ainda que de forma intuitiva, este grupo se aproxima do que neste estudo consideramos como currículo, ou seja, um processo de significação a partir do contexto da escola, entendendo que esse processo de significação compreende as "formas" de significar o mundo, a cultura, o social. É um processo, portanto, provisório e contingente e, por isso "torna inóqua distinções como currículo formal, vivido, oculto. Qualquer manifestação do currículo, qualquer episódio curricular, é a mesma coisa: a produção de sentidos” (Lopes; Macedo 2011, p.42).

\section{CONSIDERAÇÕES FINAIS}

Como dito anteriormente, não há consenso sobre o entendimento de "currículo" ainda que nos aproximemos da abordagem discursiva. O nosso entendimento é o de que essa significação não é um "fechamento" ou a "melhor" abordagem. É apenas a sinalização de uma abordagem possível, uma opção teórica, política epistemológica dentro do vasto campo de estudos de Currículo.

Todavia, no período dessa pesquisa na escola, percebemos que a falta de diálogo entre os professores e gestores contribuiu para uma visão fragmentada de Currículo. Ainda que as concepções teóricas dos professores fossem muito diferentes entre si, a possibilidade de ocasiões de diálogo foi escassa o que pode ter contribuído ainda mais com o distanciamento pedagógico entre os professores. Tal aspecto também nos remete a pensar na produção dos sentidos de Currículo na escola, tão diversificada de acordo com os entendimentos sinalizados pelos professores.

Nesse sentido, também destacamos dois grandes desafios que vislumbramos no decorrer do período desta pesquisa: a produção de currículo no contexto da prática da escola e a produção da política curricular, significada aqui de contexto de produção de texto (Ball 1994) e localizada na Secretaria Municipal de Educação de Mangaratiba. Por um lado, o desafio da gestão da escola e de professores em dialogar a respeito da produção curricular na escola, problematizar matérias, conteúdos, práticas pedagógicas, os sentidos defendidos na escola para seus murais, festas e como disse o narrador 11 "tudo o que a gente aprendeu (...) vivenciou". Por outro lado, o desafio das propostas das políticas municipais da SME e os sentidos recriados em cada escola. Apesar de haver uma rede municipal de Educação que busca projetar sentidos para as escolas, pertencer à mesma rede municipal não é prerrogativa para construir uma unicidade curricular no contexto da prática das escolas.

Esses aspectos nos remetem à reconfiguração das políticas curriculares e ao aspecto contingencial da construção curricular na escola, ambos recontextualizados no sentido de Ball (2001) pois, "sempre que o discurso se move, há espaço para a ideologia atuar" e, por isso, pode-se dizer que 
a recontextualização ocorre no campo "oficial" e no campo "pedagógico" e, "em última análise, recriadas nos contextos da prática" (p.102).

\section{REFERÊNCIAS}

ALTHUSSER, Louis. Aparelhos ideológicos do Estado. Rio de Janeiro: Graal, 1998.

ALVES, Nilda. Nós somos o que contamos: a narrativa de si como prática de formação. In: SOUZA, Elizeu Clementino de; MIGNOT, Ana Chrystina Venancio (Orgs.) Histórias de vida e formação de professores. Rio de Janeiro - RJ: Quartet/Faperj, 2008. p.131-145.

APPLE, Michael. Educação e poder. Porto Alegre: Artes Médicas, 1989.

BALL, Stephen J. The policy process and the process of policy. In: BOWE, Richard; BALL, Stephen; GOLD Anne (orgs.). Reforming education \& changing school: case studies in policy sociology. Londres/Nova Iorque: Routledge, 1992.

BALL, Stephen J. What is policy? Texts, trajectories and toolboxes. In: Education Reform: A critical and poststructural approach. Buckingham: Open University Press, 1994.

BALL, Stephen J. Diretrizes Políticas Globais e Relações Políticas Locais em Educação. Currículo sem Fronteiras, Porto Alegre, v.1, n.2, PP.99-116, jul/Dez, 2001.

BAUDELOT, Christian; ESTABLET, Roger. L'école capitaliste em France. Paris: F. Maspero, 1971.

BOURDIEU, Pierre; PASSERON, Jean Claude. A reprodução. Rio de Janeiro: Francisco Alves, 1975.

BOWLES, Samuel; GINTIS, Herbert. Schooling in capitalist America. Londres: Routledge, 1976.

BRASIL. Lei de Diretrizes e Bases da Educação Nacional 9394/96. Brasília, 1996.

BRUNER, Jerome. Atos de significação. 2. ed. Trad. Sandra Costa. São Paulo: Artmed, 2002.

BURITY, Joanildo Albuquerque. Discurso, política e sujeito na teoria da hegemonia de Ernesto Laclau. In: MENDONÇA, Daniel de; RODRIGUES, Léo Peixoto (orgs.). Pós-Estruturalismo e Teoria do Discurso: em torno de Ernesto Laclau. Porto Alegre: ediPUCRS, 2008.

CHERRYOLMES, Cleo H. Um projeto social para o currículo: perspectivas pós-estruturais. In: SILVA, Tomás Tadeu da (org.). Teoria educacional crítica em tempos pós-modernos. Porto Alegre: Artes Médicas, 1993.

CRAVEIRO, Clarissa Bastos. Políticas curriculares para formação de professores: processos de identificação docente (1995-2010). 2014. Tese (Doutorado em Educação) - UERJ, Rio de Janeiro, 2014.

FOUCAULT, Michel. A ordem do discurso. 9. ed. São Paulo: Loyola, 2003.

GOLDENBERG, Mirian. A arte de pesquisar: como fazer pesquisa qualitativa em Ciências

Sociais. 8a ed. Rio de Janeiro: Record, 2004.

HALL, Stuart. A identidade cultural na pós-modernidade. Rio de Janeiro: DP\&A, 2006.

LOPES, Alice Casemiro; MACEDO, Elizabeth. Teorias de Currículo. Cortez, São Paulo, 2011.

MAINARDES. Jefferson. Abordagem do ciclo de políticas: uma contribuição para a análise de políticas educacionais. Educ. Soc., Campinas, vol. 27, n. 94, p. 47- 69, jan./abr. 2006. Disponível em: 〈http://www.cedes.unicamp.br>. Acesso em: 23 jan. 2018. 
MENDONÇA, Daniel de; RODRIGUES, Léo Peixoto (orgs.). Pós-Estruturalismo e Teoria do Discurso: em torno de Ernesto Laclau. Porto Alegre: ediPUCRS, 2008.

MUYLAERT Camila Junqueira; SARUBBI Jr., Vicente; GALLO, Paulo; ROLIM, Modesto Leite; REIS, Alberto Olavo Advincula. Entrevistas narrativas: um importante recurso em pesquisa qualitativa. Revista da Escola de Enfermagem da USP, vol. 48, núm. 2, 2014, pp. 193-199 Universidade de São Paulo São Paulo, Brasil.

PAIVA, Vera Lucia Menezes de Oliveira e. A pesquisa narrativa: uma introdução. Revista Brasileira de Linguística Aplicada. v. 8, n.2, Belo Horizonte: Faculdade de Letras, 2008.

YOUNG, Michael. Knowledge and control. London: Macmillan, 1971. 


\section{SENTIDOS DE CURRÍCULO NA ESCOLA MUNICIPAL GLAUBER DOS SANTOS BORGES: O QUE DIZEM OS PROFESSORES}

RESUMO

Este texto compartilha uma pesquisa sobre sentidos de Currículo em uma escola municipal localizada na Costa Verde do Estado do Rio de Janeiro. Repensa a produção curricular com os professores, no contexto da prática da escola. Os objetivos dessa pesquisa são: ampliar o entendimento de currículo com os professores da escola e articular a teorização do Ciclo de Políticas de Stephen Ball. Utilizamos o referencial teórico de Alice C. Lopes e Elizabeth Macedo para pensar a produção curricular e S. Ball como possibilidade heurística de análise dos contextos da escola. Concluímos que a diversidade da produção de currículo no contexto da prática escolar é um dos aspectos que contribui para a reconfiguração das políticas curriculares.

Palavras-chave: Currículo; Escola; Formação de Professores.

\section{SENTIDOS DE CURRICULUM EN LA ESCUELA MUNICIPAL GLAUBER DOS SANTOS BORGES: QUÉ DICEN LOS PROFESORES}

RESUMEN

Esta es una investigación sobre sentidos de Currículo en una escuela ubicada en la Costa Verde en RJ, Brazil. Se repiensa el curriculo con los profesores, en la práctica escolar. Son los objetivos: ampliar la comprension de currículo con los profesores y articular la teoría del Ciclo de Políticas de Stephen Ball. Utilizamos Alice Lopes y Elizabeth Macedo para analizar la producción curricular y S. Ball como parte heurística del análisis de los contextos de la escuela. Concluimos que la diversidad en la producción de currículo en el contexto de la práctica escolar es uno aspecto que contribuye a la reconfiguración de las políticas de currículo.

Palabras clave: Currículo; escuela; Formación de profesores.

\section{CURRICULUM MEANINGS IN THE GLAUBER DOS SANTOS BORGES MUNICIPAL SCHOOL: WHAT TEACHERS SAY} ABSTRACT

This text shares a research about Curriculum meanings in a municipal school located in Costa Verde, RJ, Brazil. It rethinks the curricular production with teachers, in the context of school practice. The objectives of research are: to broaden the understanding of curriculum with teachers and articulate Stephen Ball's Policy Cycle theory. We used the theoretical reference of Alice Lopes and Elizabeth Macedo to think about the curricular production and S. Ball as a heuristic analysis possibility in school. We conclude that diversity of curriculum production in the context of school practice is one aspect that contributes to the reconfiguration of curricular policies.

Keywords: Curriculum; School; Teacher training. 